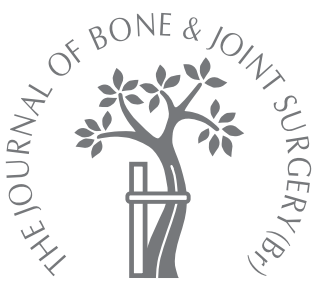

P. Moonot, P. J. Singh, M. D. Cronin, Y. E. Kalairajah, T. G. Kavanagh, R. E. Field

From South West London Elective Orthopaedic Centre, Epsom and St Helier Hospital NHS Trust, Epsom, Surrey, England

\title{
Birmingham hip resurfacing
}

\author{
IS ACETABULAR BONE CONSERVED?
}

Hip resurfacing is a bone-conserving procedure with respect to proximal femoral resection but there is debate in the literature as to whether the same holds true for the acetabulum. We have investigated whether the Birmingham hip resurfacing conserves acetabular bone.

Between 1998 and 2005, 500 Birmingham hip resurfacings were performed by two surgeons. Between 1996 and 2005 they undertook 700 primary hip replacements, with an uncemented acetabular component. These patients formed the clinical material to compare acetabular component sizing. The Birmingham hip resurfacing group comprised 350 hips in men and 150 hips in women. The uncemented total hip replacement group comprised 236 hips in men and 464 hips in women. Age- and gender-matched analysis of a cohort of patients for the sizes of the acetabular components required for the two types of replacement was also undertaken. Additionally, an analysis of the sizes of the components used by each surgeon was performed.

For age-matched women, the mean outside diameter of the Birmingham hip resurfacing acetabular components was $\mathbf{2 . 0 3} \mathbf{~ m m}$ less than that of the acetabular components in the uncemented total hip replacements $(p<0.0001)$. In similarly matched men there was no significant difference ( $p=0.77$ ). A significant difference was also found between the size of acetabular components used by the two surgeons for Birmingham hip resurfacing for both men $(p=0.0015)$ and women $(p=0.001)$. In contrast, no significant difference was found between the size of acetabular components used by the two surgeons for uncemented total hip replacement in either men or women $(p=0.06$ and $p=0.14$, respectively). This suggests that variations in acetabular preparation also influence acetabular component size in hip resurfacing.

Metal-on-metal resurfacing has been advocated as an option for the treatment of degenerative hip disease in young, active individuals. ${ }^{1}$ It is gaining popularity and has been approved by the relevant regulatory bodies in the United Kingdom. ${ }^{2,3}$ Surgeons undertaking hip resurfacing aim to minimise the resection of host bone ${ }^{1,4}$ and restore the normal biomechanics of the joint. ${ }^{1}$ Hip resurfacing also allows uncomplicated conversion to a stemmed primary femoral component should revision become necessary. First- and second-generation resurfacing designs failed more rapidly than conventional alternatives. ${ }^{5-10}$ Medium-term reports on the performance of third-generation designs demonstrate significantly improved survival, ${ }^{11-13}$ and it has been estimated that resurfacing will be the treatment of choice for between $10 \%$ and $15 \%$ of patients requiring hip replacement. ${ }^{14}$

Second-generation resurfacing designs, with metal-on-plastic articulations, often necessi- tated excessive resection of acetabular bone to accommodate the cemented polyethylene component. ${ }^{15,16}$ This problem was exacerbated when osteolysis complicated revision of these components. ${ }^{17}$ It was thus considered that hip resurfacing conserved femoral bone but not acetabular bone. The adoption of uncemented metal monoblock acetabular components, with a thickness of $3 \mathrm{~mm}$ should reduce the amount of acetabular reaming required to accommodate these components. Additionally, the size of the femoral head should now be the principal determinant for the preparation of the acetabulum.

In a randomised controlled study, Vendittoli et $\mathrm{al}^{18}$ showed no difference in acetabular component sizes between resurfacing and uncemented total hip replacement (THR) when comparing the Durom resurfacing with the Allofit acetabular component. In $7 \%$ of cases the surgeon increased the size of the Durom acetabular component to match the 
Table I. Acetabular components used for Birmingham hip resurfacing (BHR) and uncemented total hip replacement

\begin{tabular}{|c|c|c|c|c|c|}
\hline & BHR & Allofit & Ancafit & Trident & $\begin{array}{l}\text { All uncemented } \\
\text { total hip } \\
\text { replacements }\end{array}$ \\
\hline \multicolumn{6}{|l|}{ Men } \\
\hline Number of hips & 350 & 50 & 117 & 69 & 236 \\
\hline Mean external component diameter (mm) & 58.0 & 58.0 & 57.4 & 58.4 & 57.8 \\
\hline Standard deviation (mm) & 2.9 & 3.3 & 3.0 & 2.5 & 2.9 \\
\hline Range (mm) & 50 to 66 & 52 to 66 & 50 to 66 & 54 to 64 & 50 to 66 \\
\hline \multicolumn{6}{|l|}{ Women } \\
\hline Number of hips & 150 & 93 & 266 & 105 & 464 \\
\hline Mean external component diameter (mm) & 51.7 & 53.7 & 53.4 & 54.0 & 53.6 \\
\hline Standard deviation (mm) & 2.8 & 3.1 & 2.8 & 2.3 & 2.8 \\
\hline Range $(\mathrm{mm})$ & 44 to 60 & 50 to 68 & 46 to 64 & 44 to 60 & 46 to 68 \\
\hline
\end{tabular}

chosen femoral component. They also reported that the size of the acetabular component was significantly larger for men than women in both resurfacing and conventional hip replacement, and correlated significantly with body mass index. In an earlier study of 35 cases, Loughead et $\mathrm{al}^{4}$ identified that more bone was resected from the acetabulum in hip resurfacing than during hybrid THR, and observed that the difference was more pronounced in larger patients. To date there has been no large study comparing relative bone resection in men and women.

In order to determine whether the Birmingham hip resurfacing (BHR) (Smith \& Nephew, Bromsgrove, United Kingdom) necessitates the implantation of a larger diameter acetabular component than conventional uncemented or hybrid THR, we undertook a retrospective comparison of the sizes of acetabular components implanted in patients who received BHRs or uncemented THRs, by each of the two senior authors (REF, TGK). The sizes of the BHR acetabular components implanted were also compared to investigate any difference in technique between the two surgeons. We had two null hypotheses, first that no significant difference existed in the sizes of BHR and THR acetabular components used for men and women, and second that there was no significant difference between the sizes of the selected acetabular components selected by the two surgeons.

\section{Patients and Methods}

Between 1998 and November 2005, two surgeons (REF, TGK) working at St Helier Hospital, Carshalton, St Anthony's Hospital, Cheam, and the South West London Elective Orthopaedic Centre, Epsom, United Kingdom, implanted 500 BHRs. This was a consecutive series of patients comprising 310 men (350 hips), with a mean age at surgery of 54.8 years (22 to 89), and 128 women (150 hips) with a mean age at surgery of 53.9 years (26 to 75 ). Patients for whom the Birmingham dysplasia component was required were excluded from this study.
Between 1996 and November 2005, the same surgeons at the same hospitals implanted 700 consecutive uncemented primary THRs. Three types of acetabular component were used: 143 Allofit (Zimmer, Warsaw, Indiana), 383 Ancafit (Wright Medical, Memphis, Tennessee) and 174 Trident PSL (Stryker, Newbury, United Kingdom). This group comprised 220 men (236 hips) with a mean age at surgery of 64.7 years ( 31 to 86 ) and 411 women (464 hips) with a mean age at surgery of 65.2 years (27 to 96). The sizes of all the components used are presented in Table I.

The components. The Trident PSL acetabular component is peripherally expanded, for which the manufacturer recommends reaming size for size. The true rim diameter of this component is approximately $1.8 \mathrm{~mm}$ larger than the dimension shown on its packaging. Therefore, we corrected our data on component sizes to reflect this. The Allofit acetabular component is manufactured with circumferential elevated rings to produce an interference fit. Our measurements of this feature demonstrated that the rim diameter exceeded the stated dimension by an average of $1.5 \mathrm{~mm}$. Once again, a correction was added to our data on component size. The Ancafit and BHR components are almost identical to the stated diameters on the packaging, and these figures were used without any adjustment. Acetabular reaming was performed line to line for the Trident components, and in most BHRs and other uncemented THRs the acetabulum was reamed to $2 \mathrm{~mm}$ less than the intended implant size.

The number of each category of implant used by each surgeon is shown in Table II. Although both surgeons undertook comparable numbers of BHRs, surgeon 1 (REF) undertook approximately five times more uncemented THRs than surgeon 2 (TGK). Nevertheless, both surgeons had used all three uncemented acetabular components from the three THRs for a similar period and their relative usage of the THR implants was consistent throughout the period of the study.

In uncemented THR, resection of the femoral head and proximal part of the neck is followed by acetabular reaming which 
Table II. Details of Birmingham hip resurfacing and uncemented total hip replacements for two surgeons (REF, TGK)

\begin{tabular}{|c|c|c|c|c|c|c|}
\hline & \multicolumn{3}{|l|}{ Men } & \multicolumn{3}{|l|}{ Women } \\
\hline & Surgeon 1 & Surgeon 2 & $\overline{p-v a l u e}$ & Surgeon 1 & Surgeon 2 & $\overline{p-v a l u e}$ \\
\hline \multicolumn{7}{|l|}{ Birmingham hip resurfacing } \\
\hline Number of hips & 188 & 162 & & 75 & 75 & \\
\hline Mean age in yrs (range) & 53 (21 to 79$)$ & 56.9 (37 to 75$)$ & $<0.001$ & 51.4 (27 to 66$)$ & 56.4 (28 to 75$)$ & $<0.001$ \\
\hline $\begin{array}{l}\text { Mean external diameter of the acetabular component } \\
\text { in } \mathrm{mm} \text { (range) }\end{array}$ & $57.5(50$ to 64$)$ & $58.6(50$ to 66$)$ & $<0.001$ & $50.9(46$ to 60$)$ & 52.5 (44 to 60$)$ & $<0.001$ \\
\hline \multicolumn{7}{|l|}{ Uncemented total hip replacement } \\
\hline Number of hips & 193 & 43 & & 389 & 75 & \\
\hline Mean age in yrs (range) & 64.5 (31 to 83$)$ & $66 \quad(46$ to 86$)$ & 0.31 & $65.3(28$ to 97$)$ & 64.9 (27 to 80$)$ & 0.75 \\
\hline $\begin{array}{l}\text { Mean external diameter of the acetabular component } \\
\text { in } \mathrm{mm} \text { (range) }\end{array}$ & $57.6(46$ to 66$)$ & 58.6 (48 to 60 ) & 0.0435 & 53.7 (50 to 66$)$ & $53.2(50$ to 64$)$ & 0.147 \\
\hline
\end{tabular}

Table III. Age- and gender-matched cohort of patients

\begin{tabular}{|c|c|c|c|c|c|c|}
\hline & \multicolumn{3}{|l|}{ Men } & \multicolumn{3}{|l|}{ Women } \\
\hline & BHR $^{*}$ & $\begin{array}{l}\text { Uncemented total } \\
\text { hip replacement }\end{array}$ & p-value & BHR & $\begin{array}{l}\text { Uncemented total } \\
\text { hip replacement }\end{array}$ & p-value \\
\hline Number of hips & 73 & 73 & $\mathrm{~N} / \mathrm{A}^{\dagger}$ & 80 & 80 & N/A \\
\hline Mean age in yrs (range) & 60.8 (55 to 65$)$ & 60.7 (55 to 65$)$ & 0.87 & 59.5 (55 to 65$)$ & 59.5 (55 to 65$)$ & 0.99 \\
\hline $\begin{array}{l}\text { Mean external diameter of the acetabular } \\
\text { component in } \mathrm{mm} \text { (range) }\end{array}$ & $57.8(50$ to 64$)$ & $57.6(52$ to 64$)$ & 0.77 & 51.6 (46 to 58 ) & 53.63 (46 to 66 ) & $<0.001$ \\
\hline
\end{tabular}

depends solely on the acetabular anatomy. This was undertaken routinely by surgeons, however, they differed in their approach to acetabular preparation for BHRs. Surgeon 1 identified the maximum femoral neck diameter and prepared the proximal femur to accommodate the smallest acceptable head size. Acetabular preparation was then undertaken according to the predetermined head size. Surgeon 2 preferred to measure the femoral neck diameter and identify the minimum possible head size that could be used. The acetabulum would then be reamed to prepare an optimal bone bed prior to preparing the proximal femur for the correspondingly-sized femoral component.

Statistical analysis. Our records do not contain accurate information on the pathogenesis of degenerative changes of the hips in each patient and we are unable to provide these data.

An age- and gender-matched analysis of a cohort of patients for the sizes of the acetabular components used between the BHR and the uncemented THR groups, and between surgeons 1 and 2 was also undertaken. Statistical analysis was carried out using Microsoft Excel and GraphPad Prism (GraphPad Software, San Diego, California). Statistical comparisons of the implanted acetabular component diameter were made between the groups using an unpaired $t$-test and analysis of variance (ANOVA). Statistical comparison of gender was performed using a two-sample $t$-test with unequal variance and ANOVA. The level of significance was set at $\mathrm{p}<0.05$ for all statistical analyses. Where appropriate $95 \%$ confidence intervals $(\mathrm{CI})$ have been shown.

\section{Results}

A significant difference in the mean component diameter was found between men and women of $6.3 \mathrm{~mm}$ and $4.2 \mathrm{~mm}(\mathrm{p}<0.0001,95 \%$ CI 5.75 to 6.86$)$ for BHR and uncemented THR groups, respectively (Table I). On the basis that this demonstrated two discrete populations within our dataset, all further results were analysed by gender rather than by the whole population.

The mean component sizes, by gender and component type for the BHR and uncemented THR groups, are shown in Table I. Comparison of mean component size, for the BHRs and the uncemented THRs showed that for men the acetabular component size was almost identical, at $58 \mathrm{~mm}$ and $57.8 \mathrm{~mm}$, respectively ( $\mathrm{p}=0.49,95 \%$ CI 0.3 to 0.7 ). For women, the mean size of the BHR acetabular component was significantly smaller than those used in the uncemented THRs at $51.7 \mathrm{~mm}$ and $53.6 \mathrm{~mm}$, respectively ( $\mathrm{p}<0.0001,95 \%$ CI 1.4 to 2.4$)$.

The mean age of the patients with uncemented THRs was 64.7 years ( 31 to 86 ) for men and 65.2 years ( 27 to 96 ) for women, compared with mean ages of 54.8 years (22 to 89) for men and 53.9 years (26 to 75 ) for women in the respective BHR groups. For further comparison between BHR and uncemented THR groups we produced genderand age-matched cohorts. The mean component sizes, by gender and age for these subgroups, are shown in Table III. No statistical difference was identified for male patients in 
Table IV. Acetabular component sizes used by each surgeon (REF, TGK) for an age- and gender-matched cohort

\begin{tabular}{|c|c|c|c|c|c|c|}
\hline & \multicolumn{3}{|l|}{ Men } & \multicolumn{3}{|l|}{ Women } \\
\hline & Surgeon 1 & Surgeon 2 & p-value & Surgeon 1 & Surgeon 2 & p-value \\
\hline \multicolumn{7}{|l|}{ Birmingham hip resurfacing } \\
\hline Number of hips & 188 & 115 & $\mathrm{~N} / \mathrm{A}^{*}$ & 75 & 45 & N/A \\
\hline Mean age in yrs (range) & (21 to 79 ) & (37 to 63 ) & 0.98 & $51.4 \quad$ (26 to 66$)$ & 51.4 (28 to 59$)$ & 0.99 \\
\hline $\begin{array}{l}\text { Mean acetabular outside cup diameter } \\
\text { in } \mathrm{mm} \text { (range) }\end{array}$ & 57.46 (50 to 64$)$ & 58.57 (50 to 66$)$ & 0.0015 & $50.88(46$ to 60$)$ & 52.67 (44 to 60$)$ & 0.001 \\
\hline \multicolumn{7}{|l|}{ Uncemented total hip replacement } \\
\hline Number of hips & 182 & 43 & $\mathrm{~N} / \mathrm{A}$ & 389 & 75 & $\mathrm{~N} / \mathrm{A}$ \\
\hline Mean age in yrs (range) & 66.2 (31 to 83$)$ & $66 \quad(46$ to 86$)$ & 0.81 & 65.3 (28 to 97 ) & $64.9(27$ to 80$)$ & 0.75 \\
\hline $\begin{array}{l}\text { Mean external diameter of the acetabu- } \\
\text { lar component in } \mathrm{mm} \text { (range) }\end{array}$ & 57.7 (46 to 66 ) & 58.6 (48 to 60$)$ & 0.06 & 53.7 (50 to 66$)$ & $53.2(50$ to 64$)$ & 0.14 \\
\hline
\end{tabular}

the mean acetabular component diameter, which was $57.8 \mathrm{~mm}$ and $57.6 \mathrm{~mm}$ for BHRs and uncemented THRs, respectively ( $\mathrm{p}=0.7766,95 \%$ CI 1.03 to 0.77 ), but for women the mean diameter of the BHR acetabular component was significantly smaller than used in uncemented THR, at $51.6 \mathrm{~mm}$ and $53.63 \mathrm{~mm}$, respectively $(\mathrm{p}<0.0001$, $95 \%$ CI 1.15 to 2.9 ).

To assess the influence of the different strategies followed by the two surgeons for preparing the acetabulum in BHRs we compared the diameter of the acetabular components in their respective BHR and uncemented THR groups. There were no significant differences in the mean sizes of the acetabular implants in the uncemented group for both men and women (men, 57.7 vs 58.9, $\mathrm{p}=0.0658$; women, 53.7 vs 53.2, $\mathrm{p}=0.1478$ ). However, there was a significant difference between the mean ages of the populations between the two surgeons in the BHR group. Therefore, for the BHR patients age and gender matching was performed to produce a further subgroup to compare the size of the acetabular components implanted by surgeon 1 with those implanted by surgeon 2 (Table IV). The difference in mean value for BHR acetabular components between the two surgeons for women was $1.79 \mathrm{~mm}$, which was statistically significant $(p=0.001,95 \%$ CI 0.7 to 2.8$)$. For men the mean difference in sizes of the BHR acetabular components was $1.11 \mathrm{~mm}$ which was statistically significant $(\mathrm{p}=$ $0.0015,95 \%$ CI 0.4 to 1.8 ). We analysed the relative usage of the smaller and larger acetabular component combinations that are available for each BHR femoral component. Surgeon 1 used the smaller acetabular components in $83 \%$ (219) of cases and surgeon 2 used a similar proportion of the smaller acetabular components in $81 \%$ (191) of cases.

\section{Discussion}

Our retrospective review of the work of two surgeons has shown that for men who are matched for age there was a statistical difference in the mean outer diameters of the acetabular components used for BHR and uncemented THR (Table III). In contrast, for women, matched for age, the mean diameter of the BHR acetabular components was
$2.03 \mathrm{~mm}$ smaller than that of the uncemented THRs. This difference was statistically significant ( $p<0.001$, Table III). In comparing component sizes used by the two surgeons, the uncemented THR implant size was practically identical for both genders. However, BHR acetabular component diameters differed by a mean $1.11 \mathrm{~mm}$ and $1.79 \mathrm{~mm}$ for men and women, respectively. These differences were statistically significant for men and women $(\mathrm{p}=0.0015$ and $\mathrm{p}<0.001$, respectively). This suggests that the technique employed by each surgeon influenced the sizing of the acetabular components in males and females receiving BHRs.

For the series as a whole we found that a BHR allows implantation of comparably sized implants in women, but not necessarily for men. This appears to contradict the findings of Loughead et $\mathrm{al},{ }^{4}$ who reported the use of acetabular components in BHR patients approximately $4 \mathrm{~mm}$ larger than the uncemented acetabular components in THR. However, their data were derived from groups with different proportions of men and women (men:women $=2: 1$ for BHR and 5:6 for THR). Given the generally larger male skeleton, the results of Loughead et $\mathrm{al}^{4}$ may have been a reflection of the gender distribution of their series. A direct comparison of the mean BHR acetabular component diameter between the men and women in our series has shown an even greater difference between men and women of $6.3 \mathrm{~mm}$ and for uncemented THRs men received acetabular components that were $4.2 \mathrm{~mm}$ larger than for women (Table I). Whereas Vendittoli et $\mathrm{al}^{18}$ did not show a significant difference between the sizes of acetabular components used in BHRs and THRs, the same consideration applies to a lesser degree when considering their results, which were matched for age but not gender. The male-to-female ratios in their BHR and THR groups were 1.7:1 and 2.1:1, respectively.

Our study also reveals the influence of the difference in surgical technique followed by the two surgeons in the preparation of the acetabulum for BHRs (Tables II and IV). It appears that, in borderline cases, surgeon 1 tended to reduce the size of the acetabular component, whereas surgeon 2 tended to increase the size of the femoral component. 
Loughead et $\mathrm{al}^{4}$ suggested that resurfacing would sacrifice progressively more bone as the natural femoral head diameter increased. In addition, they suggested that 'for patients with a relatively small femoral neck, a smaller resurfacing head and hence a smaller acetabular component can be implanted. Typically, these patients are women'. This observation was consistent with our results and may explain our finding that acetabular resurfacing is more bone conserving for females than for males. If the natural ratio of the head:neck diameter is greater for women than men, surgeons would have a greater opportunity to reduce the size of the femoral component for women and be obliged to increase the size for men to achieve a consistent head:neck ratio.

Further work will be required to identify optimal head neck ratios to optimise both hip function and long-term component stability.

No benefits in any form have been received or will be received from a commercial party related directly or indirectly to the subject of this article.

\section{References}

1. McMinn D, Treacy R, Lin K, Pynsent P. Metal on metal surface replacement of the hip: experience of the McMinn prosthesis. Clin Orthop 1996;329:89-98.

2. No authors listed. http://nice.org.uk/page.aspx? $0=33576$ (date last accessed 7 September 2006).

3. No authors listed. http://www.fda.gov/cdrh/mda/docs/p040033.html. (date last accessed 7 September 2006).
4. Loughead JM, Starks I, Chesney D, et al. Removal of acetabular bone in resurfacing arthroplasty of the hip: a comparison with hybrid total hip arthroplasty. J Bone Joint Surg [Br] 2006;88-B:31-4.

5. Freeman MAR, Cameron HU, Brown GC. Cemented double cup arthroplasty of the hip: a five year experience with the ICLH prosthesis. Clin Orthop 1978;134:45-52.

6. Head WC. Wagner surface replaceent arthroplasty of the hip: analysis of fourteen failures in forty-one hips. J Bone Joint Surg [Am] 1981;63-A:420-7.

7. Bell RS, Schatzker J, Fornasier VL, Goodman SB. A study of implant failure in the Wagner resurfacing arthroplasty. J Bone Joint Surg [Am] 1985;67-A:1165-75.

8. Amstutz HC, Campbell P, Kossovsky N, Clarke IC. Mechanism and clinical significance of wear debris-induced osteolysis. Clin Orthop 1992;276:7-18.

9. Howie DW, Cornish BL, Vernon-Roberts B. Resurfacing hip arthroplasty: classification of loosening and the role of prosthesis wear particles. Clin Orthop 1990;255:144-59.

10. Amstutz HC, Grigoris P, Dorey FJ. Evolution and future of surface replacement of the hip. J Orthop Sci 1998;3:169-86.

11. Pollard TCB, Baker RP, Eastaugh-Waring SJ, Bannister GC. Treatment of the young active patient with osteoarthritis of the hip: a five- to seven-year comparison of hybrid total hip arthroplasty and metal-on-metal resurfacing. J Bone Joint Surg [Br] 2006:88-B:592-600

12. Hing CB, Back DL, Bailey M, et al. The results of primary Birmingham hip resurfacings at a mean of five years: an independent prospective review of the first 230 hips. $J$ Bone Joint Surg [Br] 2007;89-B:1431-8.

13. Treacy RBC, McBryde CW, Pynsent PB. Birmingham hip resurfacing arthroplasty: a minimum follow-up of five years. J Bone Joint Surg [Br]2005;87-B:167-70.

14. No authors listed. Device Reconstructive Device Series Global Markets for Hip Reconstructive Device GHIR02, September 2002. Millennium Research Group. http:// www.mrg.net (date last accessed 7 September 2006).

15. Amstutz HC, Dorey F, O'Carroll PF. THARIES resurfacing arthroplasty: evolution and long-term results. Clin Orthop 1986;213:92-114.

16. Thomas BJ, Amstutz HC. Revision surgery for failed surface arthroplasty of the hip. Clin Orthop 1982;170:42-9.

17. Head WC. The Wagner surface replacement arthroplasty. Orthop Clin North Am 1982;13:789-97.

18. Vendittoli PA, Lavigne M, Roy AG, Girard J. Removal of acetabular bone in resurfacing arthroplasty of the hip. J Bone Joint Surg [Br] 2006;88-B:838-9. 